\title{
EVALUATION OF TOPSOIL IRON OXIDE FROM VISIBLE SPECTROSCOPY
}

\author{
Binny Gopal ${ }^{1}$, Amba Shetty ${ }^{2}$ \\ 1,2, Department of Applied Mechanics and Hydraulics, National Institute of Technology, Surathkal, Karnataka, \\ 575025, India, binnygopal@gmail.com
}

\begin{abstract}
Conventional methods of soil iron oxide estimation are laborious and costly. Reflectance spectroscopy provides a good alternative that may be used to replace conventional methods of soil analysis. Most of the studies are concentrated on near infrared region of the spectrum. But in developing countries like India affording for wider range spectroscopy is a costly affair. Hence this study was conducted to establish relationship between topsoil iron oxide and their visible reflectance spectra in lateritic type of soils. Visible reflectance spectra of the soil samples were measured by a spectroradiometer in the range of 325 to $1100 \mathrm{~nm}$ with a $1 \mathrm{~nm}$ increment. Multivariate PLSR method was used to predict iron oxide from reflectance which resulted in moderate prediction of $R^{2} 0.71$ and 0.62 for calibration and validation respectively. It can be inferred that visible spectroscopy can be effectively used for topsoil iron oxide prediction with an acceptable level of accuracy.
\end{abstract}

Keywords: Topsoil, iron oxide, visible spectrum, Partial Least Square Regression.

\section{INTRODUCTION}

Iron oxides are important soil pigments which affect soil nutrient uptake by plants. Conventional methods of iron oxide estimation is labour-intensive and costly. Remote sensing and reflectance spectroscopy provides a good alternative that may be used to replace conventional methods of soil analysis. Space-borne and airborne sensor data have been used to establish relation between soil attribute and reflectance. They yielded good correlation between reflectance and topsoil iron oxide by and large to fields of larger and homogeneous units. Potential of Landsat TM data were explored to predict and map iron oxide ([15], [16] and [8]). [1] studied the possibility of CASI sensor to predict iron in sand dunes. [7] also studied iron oxide, other mineralogical and chemical composition using Airborne Visible/InfraRed Imaging Spectrometer (AVIRIS). [2] showed that it is possible to account for iron using hyperspectral HypMap data Since data obtained from spaceborne and airborne sensors contain noises, lab based spectroscopy have better advantage. Studies have been also carried out to explore the potential of spectroscopy to predict soil iron oxide. Spectroscopy with spectral range of VIS - NIR (Visible -Nearinfared) was explored to establish relationship between iron and reflectance ([3], [2]). Mid infrared region were also used for iron oxide prediction [6]. Since elements and instruments for measuring visible light have simpler structure and cheaper price, it would be easier to build an optimum model for content with visible spectral reflectance than that with NIR spectral reflectance [11].

Various calibration methods have been used to relate spectral reflectance with measured properties of materials. Principal Components Regression (PCR), Partial Least
Squares Regression (PLSR), Stepwise Multiple Linear Regression (SMLR) and Artificial Neural Networks are the most used multivariate calibration techniques. None of these proposed calibration techniques have achieved universal acceptance because a calibration model that works well for one application may be unacceptable for another [3]. PLSR is considered as a robust technique which takes care of colinearity of predictor variables and accounts for both the $\mathrm{x}$ and $\mathrm{y}$ variable to predict soil property [10], [12]. Exclusively visible region has not been explored for iron oxide prediction to the best of our knowledge. In developing countries like India affording for wider range spectroscopy is a costly affair. This poses a challenge to predict iron oxide from visible spectroscopy

\section{MATERIALS AND METHODS}

\subsection{Study area}

The study area is situated in the coastal zone, covering a part of Dakshina Kannada and Udupi Districts, southwest region of Karnataka state, India. The study area covers $47 \mathrm{~km} 2$ with the location being in longitude between $74^{\circ} 46^{\prime} 30^{\prime \prime}$ to $74^{\circ} 51^{\prime} 00^{\prime \prime}$ and latitude between $13^{\circ} 09^{\prime} 00^{\prime \prime}$ to $13^{\circ} 01^{\prime} 30^{\prime \prime}$ (Fig. 1). Land use of the present study area comprises of agricultural land, built up land, roads and vegetation. The study area mainly falls on either side of the National Highway-48 and the western part of the study area passes along the seashore. The geology of the study area is characterized by hard laterite in hilly tracts and sandy soil along the seashore 


\subsection{Data}

Only paddy fields were the target of interest. Since paddy fields were very random and dispersed here and there as a small patch of land, adopting grid sampling technique was difficult. Hence stratified random sampling method was adopted. A total of 156 samples were collected based on availability of harvested paddy field and lack of vegetation. Top 0-20 cm of soil was collected at each location during the first week of March 2012. A mixture of soils taken at 5 spots of radius $10 \mathrm{~m}$ at a location represented one sample. Soils were air dried and ground to pass through 200 micron sieve. The laboratory analysis was carried out for 156 samples to find iron oxide by spectrophotometric estimation of iron (IS CODE: 15556:2005), in soil.

\subsection{Spectral Analysis and Pre-processing of Spectral data}

All soil samples were air dried and sieved through a $2 \mathrm{~mm}$ sieve in order to remove any effect of particle size before measuring reflectance, and the soil was set in a Petri dish and the surface was leveled by ruler. Spectral reflectance (R) was measured for all soil samples by using a spectroradiometer (ASD FieldSpec HandHeld system, spectrum is $325-1075 \mathrm{~nm}$, and spectral resolution is $1 \mathrm{~nm}$ ). The instrument was mounted on a tripod with $30 \mathrm{~cm}$ distance from soil sample and an external halogen light source was used. It was optimized and calibrated with white reference panel. 5 readings were taken and then the mean spectra were got by using ViewSpec pro version.

\subsection{Partial Least Square Regression}

PLSR method emerged from studies of the flaws in MLR and in PCR [5]. The PLSR method extracts orthogonal linear combinations of predictors, known as factors, from the predictor data that explain variance in both the predictor variables and the response variables. It determines the number of factors to include in a fitted model by either. Fits the model with the determined number of factors by calculating parameter estimates of the linear regression.

\section{RESULTS AND DISCUSSIONS}

Iron oxide content in the study area ranges from $0.001 \%$ to $0.24 \%$. Descriptive statistics is given in Table 1 .

Table -1: Descriptive statistics of topsoil iron oxide content.

\begin{tabular}{|l|l|l|l|}
\hline Min & Max & Mean & Std Dev \\
\hline 0.001 & 0.24 & 0.07 & 0.06 \\
\hline
\end{tabular}

PLSR considers the whole spectra and reduces to give few components further predicting iron oxide. It accounts for both the $\mathrm{x}$ (reflectance) and $\mathrm{y}$ (iron oxide) variable and takes care of co-linearity [9]. Cross validation was carried out during calibration of model. PLSR model used 9 factors to predict iron oxide from reflectance. Selection of components was carried out by computing estimated mean square error prediction. PLSR model statistics are given in Table 2. The model with the lowest Root Mean Square Error (RMSE) is chosen as statistically the best for iron oxide prediction. PLSR analysis is carried out in MATLAB ${ }^{\circledR}$ software to establish relationship between soil iron oxide and hyperspectral data. A total of 121 samples are considered for analysis after removing outliers out of which, 87 are chosen for calibration and 34 for validation through random selection. An R2 of 0.71 was observed for calibration (Fig. 2) and 0.62 for validation (Fig. 3). RMSE of 0.04 for calibration and 0.05 for validation were observed. It can be inferred that iron oxide can be predicted to a moderate level of accuracy. The results obtained from this study are compared with the few published results available across the globe (Table 3).

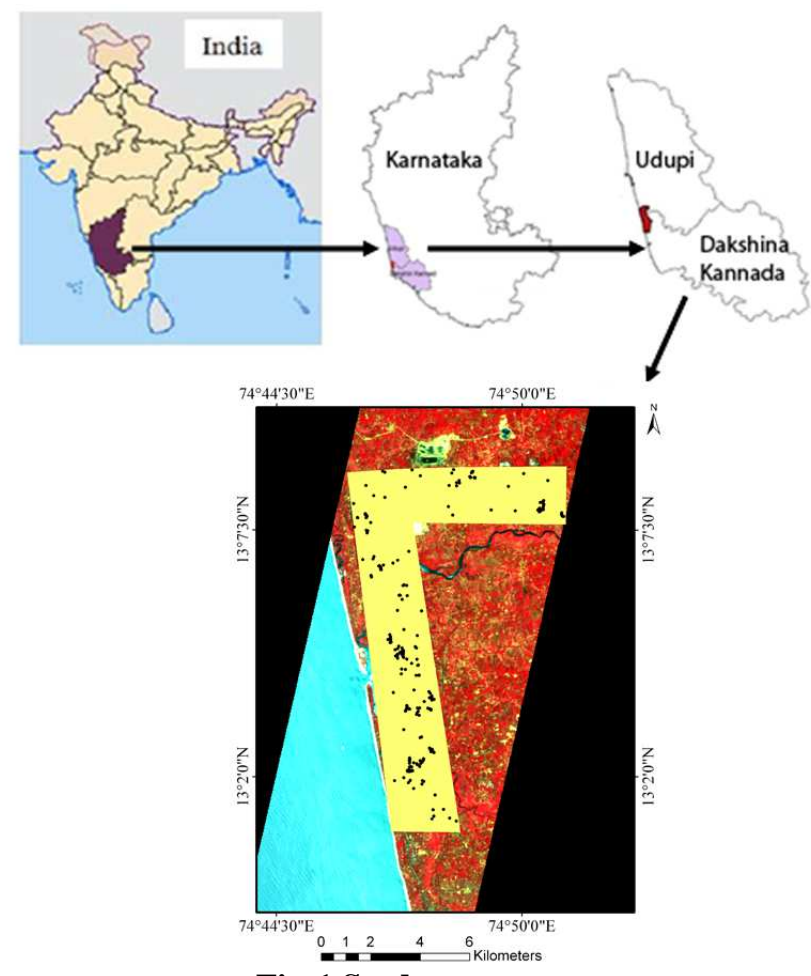

Fig-1 Study area

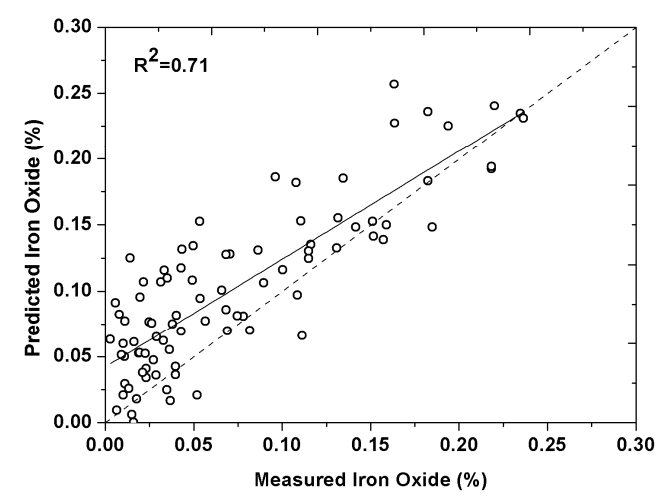

Fig -2: Result of calibration. 


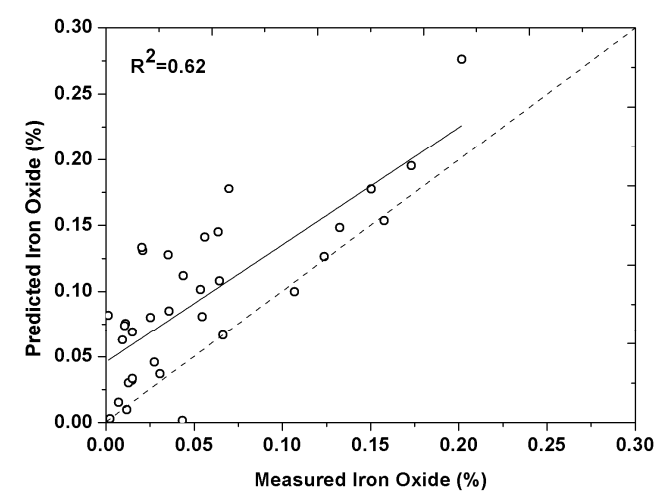

Fig -3: Result of validation.

Table- 2: PLSR model statistics.

\begin{tabular}{|c|l|l|l|l|}
\hline \multirow{2}{*}{$\begin{array}{c}\text { No of } \\
\text { PLSR } \\
\text { factors }\end{array}$} & \multicolumn{2}{|c|}{ Calibration } & \multicolumn{2}{c|}{ Validation } \\
\cline { 2 - 5 } $\mathrm{R}^{2}$ & RMSE & $\mathrm{R}^{2}$ & RMSE \\
\hline 9 & 0.71 & 0.045 & 0.62 & 0.055 \\
\hline
\end{tabular}

Table- 3: Review of iron oxide prediction.

\begin{tabular}{|l|l|l|l|l|l|}
\hline $\begin{array}{l}\text { Range } \\
\%\end{array}$ & $\begin{array}{l}\text { Std } \\
\text { Dev }\end{array}$ & $\begin{array}{l}\text { Spectral } \\
\text { range }\end{array}$ & $\begin{array}{l}\text { Statistical } \\
\text { methods }\end{array}$ & $\begin{array}{l}\text { Result } \\
\left(\mathrm{R}^{2}\right)\end{array}$ & Author \\
\hline $0.4-2.3$ & 0.6 & $\begin{array}{l}\text { NIR } \\
400- \\
2500 \mathrm{~nm} .\end{array}$ & MLR/PLSR & 0.9 & {$[4]$} \\
\hline $0.0005-$ & 0.011 & $\begin{array}{l}\text { (NIRS)- } \\
1300- \\
0.0646\end{array}$ & PCA & 0.64 & {$[3]$} \\
& $\begin{array}{l}2500 \\
\text { nm. }\end{array}$ & & & \\
\hline $0.8-9.5$ & 2.7 & $\begin{array}{l}\text { Mid- } \\
\text { infrared. }\end{array}$ & PLS-NN & 0.83 & {$[6]$} \\
& & $\begin{array}{l}2500 \text { to } \\
20,000 \\
\text { nm. }\end{array}$ & & & \\
\hline $0.0-2.9$ & 0.6 & $\begin{array}{l}\text { VIS- } \\
\text { NIR }\end{array}$ & PLSR & 0.78 & {$[2]$} \\
& & $\begin{array}{l} \\
400- \\
2500 \mathrm{~nm}\end{array}$ & & & \\
\hline $0.001-$ & 0.06 & $\begin{array}{l}\text { VIS- } \\
352- \\
0.24\end{array}$ & PLSR & 0.62 & $\begin{array}{l}\text { Present } \\
\text { Study }\end{array}$ \\
\hline
\end{tabular}

From Table 3 it can be seen that spectral range from visible to mid infrared has been explored to predict iron oxide. Varying amount of iron oxide, its standard deviation and multivariate models are seen. There is no much difference between the accuracy of prediction observed for visible and near-infrared region. Hence VIS spectroscopy can be used as an alternative to broader range spectroscopy. Even our results are on par with the published results. Hence from the result obtained it can be concluded that it is feasible to predict iron oxide using visible spectroscopy. Visible spectroscopy offers a cost effective, easy and faster technique to iron oxide in developing countries like India where affording for wide range of spectroscopy is difficult.

\section{CONCLUSIONS}

This study proposes that visible spectroscopy coupled with PLSR can predict topsoil iron oxide with a moderate level of accuracy. Visible spectroscopy offers a cost effective, easy and faster technique to predict iron oxide in developing countries like India where affording for wide range of spectroscopy is difficult.

\section{REFERENCES}

[1] Ben-Dor, E., Levin, T, N., Singer, A., Karnieli, A., Braun, O., and Kidron G.J.(2006). Quantitative mapping of the soil rubification process on sand dunes using an airborne hyperspectral sensor. Geoderma 131, 1-21.

[2] Cécile Gomez., Philippe Lagacherie., and Guillaume Couloum. (2012). Regional predictions of eight common soil properties and their spatial structures from hyperspectral Vis-NIR data. Geoderma, 189-190,176-185.

[3] Chang, C.W., Laird, D.A., Mausbach, M.J., and Hurburgh, C.R. (2001). Near-Infrared Reflectance Spectroscopy-Principal Components Regression Analyses of Soil Properties. Soil Sci Soc Am J, 65, 480-490.

[4] Diane F. Malley., Laila Yesmin., David Wray and Scott Edwards. (1999). Application of near-infrared spectroscopy in analysis of soil mineral nutrients. Communications in Soil Science and Plant Analysis, 30(7\&8), 999-1012.

[5] Geladi, P., and Kowalski, B.R. (1986). An Example Of 2-Block Predictive Partial Least-Squares Regression with Simulated Data. Analytica Chimica Acta, 185, 19-32.

[6] Janik, L.J., Forrester, S.T., and Rawson, A. (2009). The prediction of soil chemical and physical properties from mid-infrared spectroscopy and combined partial leastsquares regression and neuralnetworks (PLS-NN) analysis. Chemometrics and Intelligent Laboratory Systems, 97, 179188.

[7] Lênio Soares Galvão., Antônio Roberto Formaggio., Eduardo Guimarães Couto., and Dar A. Roberts. (2008). 
ISPRS Journal of Photogrammetry \& Remote Sensing, 63, 259-271.

[8] Madeira, J., Bedidi, A., Cervelle, B., Pouget, M., and Flay, N. (1997). Visible spectrometric indices of hematite $(\mathrm{Hm})$ and goethite (Gt) content in lateritic soils: the application of a thematic mapper (TM) image for soilmapping in Brasilia, Brazil. International Journal of Remote Sensing 18 (13), 2835-2852.

[9] Naes, T., Isaksson, T., Fearn, T., and Davies, T. (2002). A User-Friendly Guide to Multivariate Calibration and Classification. NIR publications, Chichester, UK.

[10] Pullanagari, R. R., Yule, I. J., Tuohy, M. P., and Hedley, M. J.( 2012). In-field hyperspectral proximal sensing for estimating quality parameters of mixed pasture. Precision Agriculture ,13, 351-369.

[11] Song, H., and He, Y. (2005). Evaluating Soil Organic Matter with visible spectroscopy. Proceeding of the IEEE Instrumentation and Measurement Technology Conference IMTC 2005, Ottawa, Ont, 2, 1321-1324. doi: 10.1109/IMTC.2005.1604362.

[12] Tiezhu Shi., Lijuan Cui., Junjie Wang., Teng Fei., Yiyun Chen., and Guofeng Wu. (2013). Comparison of multivariate methods for estimating soil total nitrogen with visible/near-infrared spectroscopy, Plant Soil, 366, 363-375.

[13] Volumetric and spectrophotometric estimation of iron. (2005). Indian Standard CODE:15556-2005.

[15] White, K., Walden, J., Drake, N., Eckardt, F., and Settle, J. (1997). Mapping the iron oxide content of dune sands, Namib Sand Sea, Namibia, using Landsat Thematic Mapper data. Remote Sensingof Environment, 62, 30- 39.

[16] White, K., Goudie, A., Parker, A., and Al-Farraj, A. (2001). Mapping the geochemistry of the Northern Rub' Al Khali using multispectral remote sensing techniques. Earth Surface Processes and Landforms 26, 735- 748.

\section{BIOGRAPHIES}

Dr. Amba Shetty received $\mathrm{PhD}$ degree from NITK, Surathkal. Her research interest includes ground water modeling, remote sensing and GIS.

Miss Binny Gopal is a Research Scholar working on soil remote sensing. 